\title{
Relato de experiencia: Encerrando o Processo de Monitoramento dos Casos em uma Unidade Ambulatorial - A correlação entre o risco identificado na classificação inicial e desfecho final. Avaliação e Qualidade do Cuidado
}

\section{INTRODUÇÃO:}

Instrumentos de rastreio que possam evidenciar as necessidades de acompanhamento e evolução dos casos atendidos, incluindo as causas dos casos de óbitos, permitem analisar todo o processo de atendimento que o paciente recebeu durante o período em que esteve sob os cuidados nos serviços de saúde.

A partir dos casos admitidos, classificados de acordo com o risco definido no protocolo institucional e monitorados na linha de cuidado gerontológica do ambulatório de geriatria introduzimos a analise dos casos identificados como óbito.

OBJETIVO: apresentar os resultados das análises dos casos de óbitos avaliados pela comissão de análise de obtidos de um ambulatório Especializado no atendimento a idosos e correlação entre o óbito e o risco que o paciente foi classificado na admissão.

\section{DESENVOLVIMENTO:}

Utilizamos como instrumento norteador o Relatório de Verificação de óbitos disponível no Programa Brasileiro de Segurança do Paciente-PBSP. Analise dos registros nos prontuários, sistema de agendamento e contato via telefônico com familiares para levantamento das causas dos óbitos identificados dos pacientes inseridos na linha de cuidado gerontológica, monitorados de acordo com os critérios estabelecidos no protocolo de classificação de risco institucional, que classifica os pacientes em 3 perfis de risco de morte.

\section{RESULTADOS:}

O monitoramento dos casos e registros em prontuários no período de janeiro a outubro de 2018 pela comissão de análise de Óbitos gerou resultado de 26 casos de óbitos classificados como: 56,15\% justificados 17,78\% inesperados e 26,07\% não finalizados devido ausência de informações por insucesso no contato com os familiares e dados insuficientes para finalização do caso, entre os casos justificados 19,23\% eram casos oncológicos e 100\% estavam inseridos na linha de cuidado. Os casos foram direcionados para comissão após identificação através do monitoramento realizado pela equipe envolvida no atendimento.

\section{LIÇÕES APRENDIDAS:}

A análise dos casos permite gerar um retrato das causas de óbitos dos pacientes em acompanhamento neste serviço. Os resultados vão ao encontro com o risco identificado na classificação de admissão do paciente. O processo contribuiu para melhoria na coleta de dados, registro em prontuário e na gestão do cuidado.

REFÊRENCIAS : Desafio Zero Mortes Evitáveis 2020: Protocolo de Revisão e Análise de Óbitos - Programa Brasileiro de Segurança do Paciente Versão I. Agosto 2014. 